\title{
An International Approach to Lunar Exploration in Preparation for Mars'
}

\author{
Mindy Gallo, mgallo@alum.mit.edu, (703) 406-5634 \\ Mark Avnet, avnet@alum.mit.edu, (202) 412-4264 \\ David Broniatowski,david@mit.edu, (617) 852-5006 \\ International Space University, Summer Session Program 2004 \\ Strasbourg Central Campus \\ Parc d'Innovation \\ 1 rue Jean-Dominique Cassini \\ 67400 Illkirch-Graffenstaden \\ France
}

Abstract-The Aurora Program in Europe and The Vision for Space Exploration in the United States are representative of a shift in space policies worldwide toward the goal of human and robotic exploration. Although some details differ, these plans share a common theme of expansion of a human presence across the solar system. In particular, the plans involve near-term exploration of the Moon in preparation for eventual human missions to Mars.

Given the current relevance of the topic and the international nature of space exploration as expressed in these policies, the International Space University, with sponsorship from the European Space Agency (ESA), the National Aeronautics and Space Administration (NASA), and the Canadian technology company Optech, Inc., has assigned a group of post-graduate students and professionals the task of evaluating the Moon as a test bed for Mars. This analysis includes not only the critical technologies and operational capabilities needed for Mars exploration but also the political, legal, and social context in which the effort will be undertaken. Upon identifying the enabling concepts that can be rehearsed in the context of near-term lunar exploration, the team proposes a design for a set of lunar missions and analyzes the associated policy framework.

This paper is a summary of the more comprehensive 122page report. The team consists of 47 future space leaders from 17 countries around the world. This situation presented a unique set of challenges. Organizing a group this large and diverse to produce a single consistent report required a carefully conceived structure and a great deal of flexibility from each team member. On the other hand, with these considerable challenges overcome, the report presents a truly international, intercultural, and interdisciplinary perspective on how to extend humanity's presence beyond the confines of Earth.

\footnotetext{
${ }^{1}$ 0-7803-8870-4/05/\$20.00@ 2005 IEEE

${ }^{2}$ Version 3
}

TABLE OF CONTENTS

1. INTRODUCTION AND BACKGROUND ........................ 1

2. CuRrent EXPloRation Plans ............................... 3

3. Policy, LaW, and Social ANAlysis.................. 3

4. TECHNOLOGY AND SCIENCE ANALYSIS................. 8

5. REHEARSAL MisSIONS TO THE MOON................. 12

6. CONCLUSIONS AND RECOMMENDATIONS ........... 15

REFERENCES................................................................ 16

ACKNOWLEDGEMENTS.............................................. 16

BIOGRAPHY ........................................................... 17

\section{INTRODUCTION AND BACKGROUND}

On July 20, 1969, the United States won the space race against the Soviet Union, becoming the first nation to send human beings to the Moon. The lunar program, however, lasted only three years after the first Moon landing. Because a human landing on the Moon was a singular objective, support for the program disappeared once the goal had been achieved.

In the early twenty-first century, the impetus resulting from competition between two world superpowers no longer exists. As such, humanity needs "a new set of rationales for engaging in space exploration" [1]. The focus of the U.S. Vision for Space Exploration is to establish a permanent presence on the Moon in order to prepare for exploration of Mars and beyond [2]. The European Aurora program is aimed at putting a human being on Mars by 2033 by pursuing "a stepwise build-up of capabilities and knowledge" that includes lunar preparation [3]. Instead of being a competitive endeavor, future human space exploration will be based on a foundation of international cooperation. 
This paper is based on a report prepared by 47 postgraduate students and professionals from 17 countries at the International Space University Summer Session Program 2004 in Adelaide, Australia. The report, LunAres: International Lunar Exploration in Preparation for Mars, was sponsored by ESA, NASA, and the Canadian technology company Optech, Inc.

The report identifies the enabling elements for an initial human mission to Mars and selects those that can best be rehearsed in the context of near-term international human and robotic lunar missions. The report uses this list of enabling elements to suggest a set of lunar missions leading to an eventual human mission to Mars. The analysis includes a recommended policy, legal, and social framework in which to implement the missions [1]. The goal of this paper is to provide a concise summary of the comprehensive report.

\section{Types of Lunar Activities}

Before identifying the enabling elements for Mars exploration that can best be tested on the Moon, it is helpful to categorize all lunar activities. Table 1 defines the categories used in this paper to select the lunar activities that will help prepare for exploration of Mars [1].

"Despite the many differences between the Moon and Mars, the Moon provides an excellent laboratory in which to validate critical technologies (i.e., technology rehearsal) and to develop an understanding of the issues associated with living and working on another planetary surface (i.e., operational activity). Furthermore, certain supplemental activity, such as the inclusion of private or academic experimental payloads, will help to involve the public. This involvement will be critical if the program is to retain its funding long enough to realize the goal of landing humans on Mars" [1].
Supplemental activity that does not contribute to Mars exploration is "selected out" [1]. Much of this activity should be a critical part of lunar exploration in general, but the reasons for this do not lie within the scope of this paper. Spudis [4] discusses the reasons to go to the Moon, and Mendell [5] includes several essays on activities that can be conducted there.

\section{Baseline Human Mars Mission}

As a baseline, this paper assumes a long-stay, fast-transit Mars mission similar to the 1998 NASA reference mission [6]. The four- to six-member mixed-gender crew will spend 18 to 20 months on the surface of Mars. The mission will employ a fast-transit return to Earth, and the total mission duration will be 26 to 32 months.

\section{Mission Statement}

The mission statement of the LunAres report is:

"Select, among the identified key concepts, technologies, and systems that will enable human Mars exploration, those that can best be tested on the Moon, and suggest a framework for international lunar missions that can be carried out to validate them by 2020 . Include the enabling policy, legal, societal, and economic aspects" [1].

The remainder of this paper summarizes the LunAres report. Section 2 provides an overview of various nations' current plans for exploring the Moon and Mars. Section 3 analyzes the policy, legal, and social aspects of exploration and presents a framework in which to implement such a program. Section 4 identifies the enabling elements for Mars exploration and selects those that can best be tested on the Moon. Section 5 describes lunar missions to test the selected enabling elements. Section 6 concludes with recommendations to implement the program.

Table 1. Types of activities that can be conducted on the Moon.

\begin{tabular}{|c|c|c|c|}
\hline Activity Type & \multicolumn{2}{|l|}{ Description } & Examples \\
\hline $\begin{array}{l}\text { Technology } \\
\text { Rehearsal }\end{array}$ & \multicolumn{2}{|c|}{ Use of the Moon as a technology test bed } & $\begin{array}{l}\text { Nuclear power } \\
\text { Radiation shielding } \\
\text { Space suits }\end{array}$ \\
\hline $\begin{array}{l}\text { Operational } \\
\text { Activity }\end{array}$ & \multicolumn{2}{|c|}{ Lunar activity directly applicable to Mars } & $\begin{array}{l}\text { Physiological effects } \\
\text { Psychosocial aspects } \\
\text { Living and working }\end{array}$ \\
\hline \multirow[t]{2}{*}{$\begin{array}{l}\text { Supplemental } \\
\text { Activity }\end{array}$} & \multirow{2}{*}{$\begin{array}{l}\text { Lunar activity that } \\
\text { does not directly } \\
\text { contribute to Mars } \\
\text { exploration and } \\
\text { has... }\end{array}$} & $\begin{array}{l}\text {...indirect } \\
\text { applicability to } \\
\text { Mars exploration }\end{array}$ & $\begin{array}{l}\text { Private or academic experimental } \\
\text { payloads }\end{array}$ \\
\hline & & $\begin{array}{l}\text {...little or no } \\
\text { applicability to } \\
\text { Mars exploration }\end{array}$ & Lunar astronomy \\
\hline
\end{tabular}




\section{Current Exploration Plans}

Although NASA and ESA are the only space agencies with plans for human missions to the Moon and Mars, a number of others are planning robotic missions that can provide an important contribution to the exploration effort. These space agencies are the Japanese Aerospace Exploration Agency (JAXA), the Russian Space Agency (RSA), the Canadian Space Agency (CSA), the Indian Space Research Organization (ISRO), and the China National Space Administration (CNSA).

As part of the Vision for Space Exploration, NASA is planning a lunar orbiter in 2008 and a lander in 2009. After these missions, NASA plans to send one additional lunar mission each year. The first human mission to the Moon is to take place between 2015 and 2020. In addition, the United States is planning several robotic missions to Mars. The rovers Spirit and Opportunity have been exploring the martian surface since January 2004. Human Mars missions, however, are not specifically planned. Instead, these missions will be based on experience gained during the course of human lunar exploration [1].

The European Space Agency launched the SMART-1 lunar probe in September 2003, and the probe is due to arrive in early 2005. In addition, ESA has a Mars orbiter, Mars Express, which reached the planet in December 2003 [1]. In the coming decades, ESA is planning a number of other missions to prepare for an eventual human landing on Mars in or around 2033. The latest revision of the Aurora program includes a human lunar mission tentatively scheduled for 2024 [3].

Japan currently has a lunar mission, LUNAR-A, scheduled for launch in 2005. The primary purpose of this mission is to investigate the Moon's interior in order to understand its origin and evolution. In 2006, Japan will launch the largest lunar robotic mission since the Apollo program. This mission, the Selenological and Engineering Explorer (SELENE), will make observations that can contribute to future exploration. SELENE's follow-up mission, SELENE $\mathrm{B}$, is currently a proposal. The mission is intended to demonstrate lunar landing capabilities and to deploy an autonomous rover [7], [8].

Russia does not have any current plans to explore the Moon, but the nation has a history of long-duration human spaceflight that will be critical to enabling international programs of exploration. In addition, Russia is planning a sample return mission to Phobos, one of the two moons of Mars. The Phobos-Grunt mission is scheduled for launch in 2009 [1].

Canada does not have any particular plans for lunar exploration. However, the country does plan to contribute scientific instruments to NASA's and ESA's robotic martian missions. In addition, Canada eventually would like to lead a mission to Mars [1].

India's primary purpose for accessing space is to pursue Earth-based applications. However, the country is planning a lunar orbiter, Chandrayaan-1, for launch in 2007 or 2008 [1].

In October 2003, China became the third nation to demonstrate the capability to send a human being into space. Despite this, the country has planned only robotic missions for its Chang'e lunar program [1]. This program consists of three phases: orbiter, automated soft lander/rover, and return spacecraft [9], [10]. China currently has no plans for Mars exploration but intends to use the experience acquired during the Chang'e program to contribute to international martian exploration objectives [1].

The programs described in this section, for the most part, are planned separately by each space agency without any special attention paid to redundancies or complementarities. No coordinating mechanism currently exists to ensure that the synergies among the programs are exploited. For this reason, it is unlikely that all of the programs will contribute optimally to future exploration endeavors. Therefore, the next section of this paper proposes the creation of an international coordinating body whose primary purpose is to mitigate this issue.

\section{Policy, Law, and Social Analysis}

If a space exploration program is to be sustainable among policy regimes, it must be designed and continually operated with the considerations of the legal, political, and societal realms taken into account. In the past, policy has been a primary driver for space exploration. Therefore, partners' national priorities must be accommodated in constructing any type of cooperative program [11]. Furthermore, the timescales upon which political change operates (such as budgetary and election cycles) are much shorter than the lifecycles of a sustained program for space exploration. Such a program must be able to weather these changing policies.

Legal considerations must also be recognized and accommodated in partnering arrangements because of the effect that they have on international relations. For example, the United States has strict strategic export regulations such as the International Traffic in Arms Regulations (ITAR) and the Export Administration Regulations (EAR), both of which impact the ability of partners to share information and data. 
Finally, the social ramifications of international space exploration must be taken into account to the extent possible. Social ramifications are largely important because they affect future political decisions. For example, 2019 will be the fiftieth anniversary of the first Apollo landing. It is worth noting that the U.S. Vision for Space Exploration places the first human mission to the Moon between 2015 and 2020, just in time for this anniversary. Within the context of any exploration program, the social impacts of a major disaster, such as a crewed mission failure, would seriously affect the program, potentially resulting in the cancellation of human space exploration programs.

\section{Existing Legal Frameworks}

All outer space activities take place within the framework of the existing corpus of international space law, most of which was written during the Cold War. These laws are aimed primarily at maintaining peace on Earth and avoiding the extension of superpower rivalries into outer space. Thus, these laws do not address exploration-related issues. Although the Outer Space Treaty and its companion treaties - the Liability Convention, the Rescue Convention and the Moon Treaty-do establish legal precedent for important issues (e.g., environmental sustainability on celestial bodies, non-appropriation of space, and nonweaponization of space), they are not sufficient to enable space exploration activities because of legal ambiguity or, in the case of the Moon Treaty, lack of widespread acceptance by most space-faring nations.

The UN Convention on the Law of the Sea (UNCLOS) with the 1994 Part XI Amendment is one model for a new legal framework for space exploration on the Moon and other celestial bodies. Like the Moon Treaty, most industrialized nations initially rejected UNCLOS due to equity concerns stemming from language that favored redistribution of seabed resources to developing nations. Following the 1994 Part XI Amendment to UNCLOS, which strengthened freeenterprise principles in the treaty, most industrialized nations accepted and ratified the newly amended treaty. UNCLOS is similar in to the Moon Treaty in that it cites the "common heritage of mankind" principle and institutes an International Deep-Seabed Authority as the representative of mankind that organizes and controls resource extraction activities. This effort could be a model for a possible Moon Authority to coordinate activity on the Moon [12]. Due to the similarities between the Moon Treaty and the original version of UNCLOS, it is not inconceivable that an amendment to the Moon Treaty, similar in nature to the UNCLOS Part XI Amendment, could suffice.

New regulations must also be introduced that expand upon the Liability Convention. This task includes creating provisions for dealing with liability issues in case of incidents occurring during exploration programs, as well as provisions for environmental issues dealing with the status of nature on the Moon or Mars.
It is important to establish a treaty that is applicable to the Moon, Mars, and all other celestial bodies to define the rights and obligations of entities engaged in space exploration. Adherence to such regulations throughout the international community is key to the legal realization of space exploration.

\section{Existing Cooperative Efforts}

Most space-faring nations have proposed exploration beyond low Earth orbit (LEO). As a result, a number of different approaches to space exploration exist. These programs do not consist of the development of a single end product but are successive steps that result in the building of a suite of capabilities needed to move on to the next step of exploration. Public-private partnerships (PPPs), such as the Galileo Program and the Joint Strike Fighter (JSF) Program, provide one model for international and commercial cooperation on a programmatic level. On the other hand, public-led programs, such as the International Space Station (ISS), provide examples of how international cooperation is being accomplished today. Both of these approaches are discussed below.

Public-Private Partnerships-The PPP structure may be used in the event that some aspect of the exploration program ignites commercial interest. One example of a PPP is the Galileo program, an independent European satellite navigation system that incorporates opportunities for the commercial sector. Galileo is to be one part of the satellite global positioning system-of-systems that includes the United States' Global Positioning System (GPS) and Russia's GLONASS. Although Galileo has not yet been fully deployed, the Galileo management structure and the PPP serve as examples of how a supranational organisation (EU), an intergovernmental institution (ESA), and the private sector may cooperate in the future.

The Joint Strike Fighter (JSF) PPP has been suggested in the "Aldridge Commission" report as an alternative structure for international participation in the recently proposed US space exploration program [13]. The goal of the JSF program is to produce an affordable common family of strike fighter aircraft that is interoperable among the operating countries [14]. The program structure is such that partners must "buy in" to the program as a Level I, II, or III partner, or as a Security Cooperation participant. All participating companies compete for contracts from Lockheed Martin, the prime integrator, which selects subcontractors (foreign and domestic) on the basis of technical merit and affordability. The overarching goal is to make the JSF an affordable aircraft. The arrangement among the partners is governed by Memoranda of Understanding (MOU) between the US government and each partner. The EU will not participate in a cooperative venture where "fair return" cannot be guaranteed and where the integration leadership belongs to any single private 
company; it has therefore refused to participate in this type of cooperation.

Public-led programs-The International Space Station (ISS) program is the largest international cooperation effort ever attempted. Sixteen nations cooperated to design, integrate, and operate the ISS. The ISS began with an Intergovernmental Agreement among partners that allowed four MOUs, which in turn led to a suite of multilateral and bilateral agreements [11]. The purpose of this international partnering framework was to "establish a long-term international cooperative framework among the partners, on the basis of genuine partnership, for detailed design, development, operation and utilization of a permanently inhabited civil International Space Station for peaceful purposes, in accordance with international law" [15]. This agreement identifies the partners and their rights and obligations, ownership of equipment and elements, use of ISS, a high-level management structure, and other highlevel structural issues. The USA holds the lead role for management and coordination.

\section{Suggested Cooperative Framework}

The most important lesson learned from the ISS partnering framework is that partners should be flexible in developing a future exploration framework to allow for adjustments to changing political situations and countries' priorities [15]. Because no one country can currently afford to carry the full budgetary burden of human exploration of the Moon and Mars, it may be advantageous to structure a partnering framework in which major responsibilities, such as budget and program leadership, are shared among partners. The positive aspects and the lessons learned from the ISS partnerships should be incorporated into an exploration program framework.

An integrated international organization is needed for effective management. The Working Group on "International Cooperation in the Context of a Space Exploration Vision" at the Seventh AIAA Workshop on International Space Cooperation held May 3-6, 2004 suggested the concept of "A Virtual Program of Programs" for structuring international cooperation in the exploration program. This Virtual Program, "rather than trying to develop a cooperative concept for exploration as a whole, would be comprised of a coordinated set of individual activities, each activity employing the most sensible international arrangement as determined by the specific parties involved" [10]. Not all partners would be involved in all activities, and not all activities would necessarily be cooperative. Rather, a spirit of collaboration would be upheld. This framework would incorporate the lessons learned from the ISS experience.

This paper suggests implementing a loose coordinating body called the Space Exploration Forum (SEF). The initial role of the SEF will be to maintain a database in which participating nations will register their space exploration activities, thus limiting duplication of effort and allowing exploitation of synergies among agencies' programs. This registry will be part of the public domain. Such a structure will allow nations to coordinate their space exploration activities while maintaining the prestige inherent in national activities.

Forum membership will be open to any nation willing to participate in long-term space exploration within a framework of international cooperation. The Forum will adapt to a changing political environment over the longterm by "providing its members a forum for communication, consultation and coordination, leading ideally to an alignment of national exploration programs" [11]. Agencies or separate partnerships determine the management of individual missions. The Forum facilitates these partnerships. The Forum will not have the authority to manage the missions.

Forum Substructure-It is recommended that three Advisory Boards be established under the aegis of the Forum: one for legal and ethical issues, one for societal outreach, and one for technical issues. These recommendations are not binding given the structure of the Space Exploration Forum; however, if space exploration is to be implemented in a sustainable manner, space-faring nations should make maximum use of pre-existing equipment, data, and capabilities. Forum recommendations will facilitate this endeavor.

Technical Advisory Board Role-The Technical Advisory Board will make recommendations to the Forum regarding standardization, technology harmonization, and overall mission operations coordination. To facilitate cooperation on a technological level, a common family of technical interfaces should be established for connecting space system elements. These technical interfaces would specify the way in which space systems physically interact with one another.

Definite economic advantages of standardization exist for agencies and industry [16]. Standardization serves as a costreducing mechanism for other industries and could be an enabling element in the reduction of mission cost and the modularity of space systems [17]. Standardization promotes sustainable access to space through easy replacement of system elements, assistance of one spacecraft to another spacecraft, or rescue of spacecraft. Benefits for cooperation and international subcontracting between international space industries and agencies are an aspect deserving further study. This study should include the effect of standardization on space commercialization and competition among companies; some companies may be able to develop a competitive edge by focusing on certain space hardware. For example, a company might focus on manufacturing space tugs, space tankers or resource utilization plants. 
Social Outreach Advisory Board Role-To secure longterm political sustainability, an exploration program must engage all members of society. The Social Outreach Advisory Board's role is therefore to inspire the public and to enable its sustained participation in and support for Moon and Mars exploration missions. In doing so, it will provide to the Forum recommendations aimed at highlighting the human and inspirational elements of exploration. The Board will promote programs that foster the public's sense of ownership of and participation in exploration activities.

The Social Outreach Advisory Board will serve as a source of information to the media and the public, thereby helping to keep the public well informed concerning exploration activities. The implementation of a space exploration mission registry that is part of the public domain is an example of such an information source.

The Advisory Board will also play a role in inspiring children throughout the world. For example, the large-scale international implementation of programs, such as The Planetary Society's "Red Rover, Red Rover" program, would be an ideal outreach activity for children. This program allows children to build toy rovers and operate others' rovers tele-robotically through the internet [18].

Another Social Outreach Advisory Board role is to coordinate with existing space advocacy groups, such as the American Astronautical Society (AAS), the British Interplanetary Society (BIS), The Planetary Society, and the Students for the Exploration and Development of Space (SEDS), to provide outreach activities.

Legal Advisory Board Role-Participating states will have to define the legal aspects of individual missions will have to be defined on a case-by-case basis The legal structure of individual missions will depend on the participants' needs and desires for that mission (for example, whether or not industry is directly involved through a PPP). The Legal Advisory Board will facilitate the creation of legal agreements among countries that wish to cooperate on a joint mission. The Board will define recommendations for the individual missions' legal documents and their basic legal structure.

In general, the three Advisory Boards will submit their findings in the form of a proposal to the Forum. Upon approving a proposal, the Forum will submit these findings as recommendations.

Timeline-Membership in the Forum will be voluntary. Representatives of signatory states, agencies, or other organizations that express an interest in participating in the Forum will define and approve the Forum's rules at its first meeting. Representatives from industry and societal organizations (e.g., space advocacy groups such as the Planetary Society) will be welcome as observers.
At its first meeting, the Forum will accept its rules of procedure defining detailed member rights and responsibilities. After approving the rules of procedure, the Forum will establish the three Advisory Boards, including each Board's rules of procedures and funding.

Given the current political scene in which the future of space exploration is still uncertain within most governments and agencies, establishment of a commitment by most space-faring nations to the Space Exploration Forum as described herein is premature. In the near-term, it is recommended that regular meetings occur among top-level space agency representatives so as to encourage future coordination. These meetings should culminate in the eventual formation of the Space Exploration Forum. The Forum, with all three Advisory Boards, should be fully formed as described above by the time preliminary conceptual designs for the first human lunar mission are being carried out. The first highly publicized act of the Forum should therefore be the first international human mission to the Moon.

\section{Exit and Transition Strategies for Lunar Engagement}

A viable exit strategy should be incorporated to permit nations to commit to a long-term undertaking such as a lunar engagement in preparation for Mars. Depending on the budget available to each participant, multiple scenarios are envisioned which range from abandoning the Moon completely, followed by a period of financial recovery, to funding parallel Moon and a Mars programs. The latter is unlikely due to funding constraints; therefore, once the Moon has yielded the desired experience, any exit or transition strategy must enable a smooth shift of resources towards the martian goal [19]. "Such a strategy need not terminate all support of lunar activity, but must free up sufficient resources. This issue constitutes a substantial gap in all current exploration road maps. The strategy chosen to address this deficiency will ultimately depend on the total available resources as well as on the desired timeframe and the policies concerning long-term lunar objectives." [1]

"Such a strategy would also contribute to achieving a firm commitment to an exploration program by participating parties. Having a strategy and timeline in place that clearly define how and when participants in a program can terminate, change or reevaluate their contribution, will make such a commitment more attractive than an open-ended program with non-defined total commitment. The strategy chosen will have implications for most aspects of program design, ranging from lifetime of hardware to political framework. Therefore, making a decision on how to proceed in a lunar engagement once its primary objective has been achieved should take place at an early stage of the program." [1] Table 2 describes some potential transition strategies. 
Table 2 Exit and transition strategies for lunar engagement on the way to Mars.

\begin{tabular}{|c|c|c|c|}
\hline Strategy & Description & Pro & Con \\
\hline $\begin{array}{l}\text { Minimum } \\
\text { engagement } \\
\text { strategy }\end{array}$ & $\begin{array}{l}\text { Mission and hardware are } \\
\text { designed solely around martian } \\
\text { rehearsal objectives; only semi- } \\
\text { permanent infrastructure is } \\
\text { deployed; Moon is completely } \\
\text { abandoned once desired } \\
\text { experience is gained }\end{array}$ & $\begin{array}{l}\text { Cheapest in the } \\
\text { short run; fastest } \\
\text { route to Mars }\end{array}$ & $\begin{array}{l}\text { No long--run benefit to } \\
\text { lunar development; if } \\
\text { martian program fails, } \\
\text { investment is lost; } \\
\text { danger of losing } \\
\text { operational experience } \\
\text { (OE) if transition is not } \\
\text { made quickly }\end{array}$ \\
\hline $\begin{array}{l}\text { Privatization } \\
\text { strategy }\end{array}$ & $\begin{array}{l}\text { Pass on/sell infrastructure to } \\
\text { private entity }\end{array}$ & $\begin{array}{l}\text { Lunar development } \\
\text { without expending } \\
\text { government } \\
\text { resources }\end{array}$ & $\begin{array}{l}\text { A lunar engagement } \\
\text { must be commercially } \\
\text { attractive by this time; } \\
\text { could be hard to } \\
\text { maintain ethical } \\
\text { standards }\end{array}$ \\
\hline $\begin{array}{l}\text { Self- } \\
\text { sustaining } \\
\text { presence } \\
\text { strategy }\end{array}$ & $\begin{array}{l}\text { Lunar presence is built up to the } \\
\text { stage where it becomes } \\
\text { economically self-sustaining and } \\
\text { no or only little public support is } \\
\text { required; e.g., through mining, } \\
\text { energy production, } \\
\text { manufacturing of space } \\
\text { hardware, tourism, and He3 } \\
\text { export }\end{array}$ & $\begin{array}{l}\text { Sustainability; OE is } \\
\text { maintained }\end{array}$ & $\begin{array}{l}\text { Human Mars mission } \\
\text { (HMM) is delayed } \\
\text { almost indefinitely; huge } \\
\text { investment; no proven } \\
\text { approach to achieve } \\
\text { economic self- } \\
\text { sufficiency }\end{array}$ \\
\hline $\begin{array}{l}\text { Inheritance } \\
\text { strategy }\end{array}$ & $\begin{array}{l}\text { Lunar infrastructure tailored to } \\
\text { long--term presence is built up } \\
\text { and exploited for martian } \\
\text { rehearsal; once martian program } \\
\text { is scaled up the infrastructure is } \\
\text { passed on/sold to second-- } \\
\text { generation space powers; gradual } \\
\text { transition possible }\end{array}$ & $\begin{array}{l}\text { Possibility for } \\
\text { second generation } \\
\text { powers to "earn } \\
\text { their wings"; gradual } \\
\text { transition possible; } \\
\text { OE maintained }\end{array}$ & $\begin{array}{l}\text { Questionable whether } \\
\text { politically attractive; } \\
\text { assumes not all nations } \\
\text { are fully involved in } \\
\text { martian effort }\end{array}$ \\
\hline $\begin{array}{l}\text { Staging point } \\
\text { strategy }\end{array}$ & $\begin{array}{l}\text { Moon is actively used in launch } \\
\text { of a HMM; most likely } \\
\text { propellant production by lunar } \\
\text { ISRU; launch of complete } \\
\text { mission from lunar surface } \\
\text { unlikely }\end{array}$ & $\begin{array}{l}\text { Possibly cheaper for } \\
\text { a long-term martian } \\
\text { effort; OE is } \\
\text { maintained }\end{array}$ & $\begin{array}{l}\text { Large investment; long } \\
\text { lead time }\end{array}$ \\
\hline $\begin{array}{l}\text { Parallel } \\
\text { strategy }\end{array}$ & $\begin{array}{l}\text { Both a martian and a lunar } \\
\text { program are supported at full } \\
\text { scale; resource demand is likely } \\
\text { prohibitive in the foreseeable } \\
\text { future }\end{array}$ & $\begin{array}{l}\text { Both lunar and } \\
\text { martian } \\
\text { development; OE is } \\
\text { maintained }\end{array}$ & $\begin{array}{l}\text { Likely prohibitively } \\
\text { expensive }\end{array}$ \\
\hline
\end{tabular}




\section{TeChNology AND SCIEnCE AnAlysis}

This section summarizes the differences between Mars and Moon missions, lists major enabling elements for a Mars mission, and selects those elements that can best be tested on the Moon. The list provided in Table 4 is an input to the mission design summarized in Section 5.

\section{Moon and Mars Mission Differences}

A comparison of the differences between Moon and Mars missions, by mission phase, is presented in the following section.

\section{$\underline{\text { Phase I. Earth Ground Operations }}$}

Ground operations will be similar for Moon and Mars missions for spacecraft integration, launch site preparation, and mission support operations. Crew selection and training may vary, as the Mars mission will require longer periods of isolation and therefore a more robust crew medical evaluation.

\section{Phase II. Launch to Earth Orbit}

A heavy lift launch vehicle (HLV) may be required for missions to both the Moon and Mars. Therefore, the same HLV could be used. The total launch mass and number of required launches, however, is anticipated to be higher for a Mars mission.

\section{Phase III. Near-Earth Operations}

Both lunar and martian missions may require rendezvous and docking; however, the total mass of the martian transfer vehicle will be much larger than the lunar transfer vehicle, estimated at 550 tonnes for a lunar outpost and 750 tonnes for a martian mission [20].

\section{Phase IV. Interplanetary Travel}

The delta- $\mathrm{V}$ required for a Mars mission is much greater due to its large distance from the Earth. Launch opportunities to Mars are only available every 26 months versus nearly every day for the Moon. A free return trajectory is possible for lunar but not martian missions. The duration of the Mars transfer will be on the order of 120 to 150 days versus 3 to 5 days for the Moon. Mars' increased distance from the Sun also affects solar power generation. Communications with a spacecraft en route to Mars will require more power, a larger antenna, and better pointing accuracy.

\section{Phase V. Moon/Mars Orbit Operations}

For martian missions, presence of an atmosphere allows aerocapture and aerobraking, which potentially reduces propellant needs. Additionally, mass difference between Moon and Mars will affect orbital maneuvers.

\section{Phase VI. Entry/Descent}

The Moon will require retrorockets, while the martian atmosphere allows use of aerodynamic deceleration.

\section{Phase VII. Landing}

The martian atmosphere, including wind and dust storms, will make the Mars landing distinct from a Moon landing. Additionally, geographic features differ between the two bodies.

\section{Phase VIII. On-planet Operations}

Many differences are anticipated between Moon and Mars planetary operations because of variations in the environments. Habitats, vehicles, and spacesuits will therefore be designed differently. Additionally, some aspects of the martian surface are still unknown. Communications between Earth and Mars will be more complicated. Generation of solar power on Mars is less sufficient due to dust storms and diurnal durations.

\section{Phase IX. Ascent from Moon/Mars Surface}

Differences will occur due to gravity, atmospheric pressure, atmospheric friction, and mass of the Moon/Mars ascent vehicles.

Phase X. Moon/Mars Orbit Operations

Refer to Phase V.

Phase XI. Interplanetary Travel to Earth

Refer to Phase IV.

Phase XII. Earth Orbit Operations

Insertion into Earth orbit will be similar for Mars and Moon missions.

Phase XIII. Entry, Descent, and Landing on Earth The main difference noted in this phase is the mass and trajectory of Mars/Moon returning spacecraft.

$\underline{\text { Phase XIV. Post Landing Ground Operations }}$

International agreements may require quarantine of returning Mars astronauts and hardware.

Table 3 summarizes the differences between a human mission to the Moon and Mars.

\section{Mars Mission Enabling Elements}

The following enabling elements were identified as necessary for a human or robotic mission to Mars. An "enabling element" is defined as a "technology or concept necessary to achieve a human mission to Mars" [1]. 
Table 3. Comparison: Missions to the Moon and Mars.

\begin{tabular}{|c|c|c|c|}
\hline \multirow{2}{*}{ Areas } & \multirow{2}{*}{ Elements } & \multicolumn{2}{|c|}{ Effect on Mission to } \\
\hline & & Moon & Mars \\
\hline Mission preparation & $\begin{array}{l}\text { Complexity } \\
\text { (technical, mission) }\end{array}$ & Same & Same \\
\hline Crew training & $\begin{array}{l}\text { Mission duration } \\
\text { Distance from Earth }\end{array}$ & $\begin{array}{l}\text { Short transfer } \\
\text { No special training }\end{array}$ & $\begin{array}{l}\text { Long transfer } \\
\text { Psychological testing and training } \\
\text { Emergency medical training }\end{array}$ \\
\hline Launch vehicle & $\begin{array}{l}\text { Largest structure to } \\
\text { put on surface }\end{array}$ & Same & Same \\
\hline $\begin{array}{l}\text { Rendezvous and } \\
\text { docking }\end{array}$ & $\begin{array}{l}\text { Total mass in LEO at } \\
\text { departure }\end{array}$ & Up to 550 tonnes & Up to 750 tonnes \\
\hline Assembly in space & $\begin{array}{l}\text { Total mass in LEO at } \\
\text { departure }\end{array}$ & $\begin{array}{l}\text { Can split up in several } \\
\text { single transfers }\end{array}$ & $\begin{array}{l}\text { Need more mass to sustain long-duration } \\
\text { transfer }\end{array}$ \\
\hline Orbit maneuvers & Gravitation & Less & More \\
\hline $\begin{array}{l}\text { Trans- Lunar/Mars } \\
\text { Injection }\end{array}$ & Needed $\Delta \mathrm{V}$ & $3050 \mathrm{~m} / \mathrm{s}$ (Apollo type) & $5600 \mathrm{~m} / \mathrm{s}$ (for minimal energy Hohmann) \\
\hline Trajectory & Orbit mechanics & Free return possible & Trade: transfer duration vs propellant mass \\
\hline Transfer duration & Distance & $3-5$ days & $150-300$ days \\
\hline Life support & $\begin{array}{l}\text { Mission duration } \\
\text { Resupply possible? }\end{array}$ & $\begin{array}{l}\text { Same } \\
\text { Possible (fast response) }\end{array}$ & $\begin{array}{l}\text { Same } \\
\text { No }\end{array}$ \\
\hline Communication & Distance & $\begin{array}{l}\text { Low gain } \\
\sim 2.5 \text { s round trip time }\end{array}$ & $\begin{array}{l}\text { High gain, power, accuracy } \\
\sim 20 \text { up to } 50 \text { min round trip time }\end{array}$ \\
\hline Orbit insertion & $\begin{array}{l}\Delta \mathrm{V} \text { required } \\
\text { Other possibilities }\end{array}$ & $920 \mathrm{~m} / \mathrm{s}$ & $\begin{array}{l}2000-2800 \mathrm{~m} / \mathrm{s} \\
\text { Aerocapture }\end{array}$ \\
\hline $\begin{array}{l}\text { Entry/Descent } \\
\text { vehicle }\end{array}$ & Atmosphere & $\begin{array}{l}\text { None; requires greater } \\
\text { impulsive maneuvers }\end{array}$ & Entry capsule, parachute \\
\hline Habitat & $\begin{array}{l}\text { Stay duration } \\
\text { Radiation } \\
\text { environment }\end{array}$ & $\begin{array}{l}\text { Same } \\
\text { Sometimes shielded from } \\
\text { Earth's magnetosphere }\end{array}$ & $\begin{array}{l}\text { Same } \\
\text { Interplanetary space, some shielding from } \\
\text { atmosphere }\end{array}$ \\
\hline Mobility & $\begin{array}{l}\text { Soil properties } \\
\text { Pressure } \\
\text { Gravity }\end{array}$ & $\begin{array}{l}\text { Same } \\
\text { Same } \\
1 / 6 \mathrm{~g}\end{array}$ & $\begin{array}{l}\text { Same } \\
\text { Same } \\
3 / 8 \mathrm{~g}\end{array}$ \\
\hline Power generation & $\begin{array}{l}\text { Solar flux } \\
\text { Day/night cycle }\end{array}$ & $\begin{array}{l}1368 \mathrm{~W} / \mathrm{m}^{2} \\
27.3 \text { days (except at poles) }\end{array}$ & $\begin{array}{l}589 \mathrm{~W} / \mathrm{m}^{2} \\
24.66 \text { hours }\end{array}$ \\
\hline $\begin{array}{l}\text { In-situ resource } \\
\text { utilization }\end{array}$ & $\begin{array}{l}\text { Soil composition } \\
\text { Atmosphere } \\
\text { Water }\end{array}$ & $\begin{array}{l}\text { Yes } \\
\text { No atmosphere } \\
\text { Maybe }\end{array}$ & $\begin{array}{l}\text { Yes } \\
\text { Yes } \\
\text { Maybe }\end{array}$ \\
\hline $\begin{array}{l}\text { Earth entry capsule } \\
\text { and recovery }\end{array}$ & Arrival velocity & $\begin{array}{l}11 \mathrm{~km} / \mathrm{s} \text { (direct) } \\
7.6 \mathrm{~km} / \mathrm{s} \text { (from LEO) }\end{array}$ & $\begin{array}{l}12.3 \mathrm{~km} / \mathrm{s} \text { (direct) } \\
7.6 \mathrm{~km} / \mathrm{s} \text { (from LEO) }\end{array}$ \\
\hline Quarantine & Alien life forms & Not necessary & Maybe yes \\
\hline
\end{tabular}


- Communications

- Crew comfort and welfare

- Crew rescue, safety, and survivability

- Environmental shielding

- Extravehicular activity

- Ground facilities (on Earth)

- Guidance, navigation, and control

- Integrated vehicle health management

- Mars habitat

- In Situ resource utilization

- Life support systems

- Medical issues and human physiological research

- Operations

- Planetary protection

- Power generation and storage

- Propulsion

- Psychosocial factors

- Robotics

- Science

- Thermal management

- Transportation

\section{Element Selection}

The Mars enabling elements that can be tested on the Moon were identified and ranked by identifying where the element could best be tested: Earth, LEO, in space (outside the radiation protection from the Van Allen belt), on the Moon, or only on Mars. Those elements that can best be tested on the Moon were then ranked with a grade from 1 (low) to 3 (high) based on the criteria of performance, safety, technology readiness level (TRL), cost, policy, sustainability, and scientific value. In addition, a weighting was assigned to each of the criteria. A detailed description of the enabling elements and the ranking criteria is presented in the LunAres report [1]. Table 4 lists the 45 top enabling elements that can best be tested on the Moon. The following section briefly describes the enabling elements selected in Table 4.

\section{Psychosocial Factors}

Study of psychosocial factors on the Moon will introduce two stressors not present in Earth-based or ISS-based human research: complete isolation from Earth and a reduced gravity environment. While the reduced gravity environment is less than that of Mars, the Moon's gravity environment will provide a better analog to Mars activities. Several factors in this area need to be studied and understood, including conflict resolution, group interactions, hierarchy structures, crew workload and spare time provision, and psychological countermeasures.

\section{Extravehicular Activity (EVA)}

To provide enhanced mobility and lessen astronaut fatigue during EVAs, an advanced EVA suit and life support system must be developed. Testing of these systems on the
Moon will ensure that astronauts on Mars will be able to carry out the tasks required to complete their mission.

Guidance, Navigation, and Control (GNC)

Precision landing on the Moon and Mars will require new GNC technologies due to the lack of navigation precision by means normally used (Deep Space Network or inertial systems). Surface localization and navigation systems will be necessary for rovers and humans on Mars.

\section{Transportation}

Human transportation for six to eight crewmembers on a long trip to Mars must be developed. Though missions to the Moon may not require the same vehicles, the transportation for Mars must be tested prior to initiating a Mars mission. Soft landing and precision landing will be required for the Mars mission to ensure safety and rendezvous with equipment and/or habitats sent prior to a human crew. The Moon provides an analog location to test both of these technologies.

Medical Issues and Human Physiology Research

Surface-stay countermeasures and medical procedures that will be affected by reduced surface gravity are suitable for testing on the Moon. Medical issues related to total isolation, as well as surgical procedures and radiation management, must be explored and tested on the Moon prior to a Mars mission.

\section{Habitation (Mars Surface)}

Living and working areas, greenhouses, airlocks and advanced construction materials, inflatable structures, and pre-deployed habitats are necessary for human Mars missions. Several of these technologies can easily be tested on the Moon to prove their technology readiness for a Mars mission.

\section{Environmental Shielding}

Both the Moon and Mars lack a magnetic field to protect astronauts on the surface from solar and galactic radiation. Use of regolith or natural caves for protection from radiation can be explored for applicability to Mars.

\section{Operations}

Missions to the Moon must focus on the operations necessary for a Mars mission. Maintenance, repair, and construction of rovers, habitats, and other equipment are necessary. Astronauts should be trained to perform these activities in a reduced gravity environment.

\section{Crew Rescue, Safety, and Survivability}

Safe haven and emergency training will be important to Mars missions, as it will not be possible to return astronauts in the event of a major problem (as is currently done on the ISS). The Moon provides an analog site to rehearse these scenarios. 
Table 4. Enabling elements to be rehearsed on the Moon.

\begin{tabular}{|c|c|c|c|c|c|c|c|c|c|c|}
\hline 葛 & Categories & Enabling Elements & 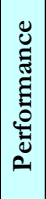 & 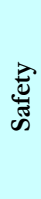 & 象 & 仓̊ & $\frac{0}{0}$ & 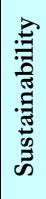 & 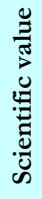 & ֻँ் \\
\hline 1 & Psycho-social Factors & Conflict Resolution & 2 & 3 & 3 & 3 & 3 & 3 & 1 & 134 \\
\hline 2 & Extravehicular Activity (EVA) & Advanced planetary suit capability & 3 & 3 & 1 & 3 & 3 & 3 & 2 & 129 \\
\hline 3 & Guidance, Navigation and Control & Precision landing & 3 & 3 & 2 & 2 & 3 & 3 & 2 & 129 \\
\hline 4 & Transportation & Soft Landing & 3 & 3 & 2 & 2 & 3 & 3 & 2 & 129 \\
\hline 5 & Medical issues \& Human Physiology research & $\begin{array}{l}\text { Isolation-related medical strategies } \\
\text { (critical care requirements, pregnancy, death) }\end{array}$ & 2 & 3 & 2 & 2 & 3 & 3 & 3 & 128 \\
\hline 6 & Medical issues \& Human Physiology research & Radiation management & 2 & 3 & 2 & 2 & 3 & 3 & 3 & 128 \\
\hline 7 & Psycho-social Factors & Crew workload \& spare time & 3 & 2 & 3 & 3 & 3 & 3 & 1 & 128 \\
\hline 8 & Psycho-social Factors & Psychological countermeasures and treatments & 2 & 3 & 2 & 2 & 3 & 3 & 3 & 128 \\
\hline 9 & Psycho-social Factors & Group structure and interactions & 2 & 3 & 2 & 3 & 3 & 3 & 1 & 127 \\
\hline 10 & Habitation (Mars Surface) & Airlocks & 3 & 3 & 2 & 2 & 3 & 3 & 1 & 125 \\
\hline 11 & Guidance, Navigation and Control & Surface navigation \& localization & 3 & 3 & 2 & 1 & 3 & 3 & 2 & 122 \\
\hline 12 & Medical issues \& Human Physiology research & Surface stay countermeasures & 2 & 3 & 1 & 2 & 3 & 3 & 3 & 121 \\
\hline 13 & Environmental shielding & Regolith, caves (radiation) & 2 & 3 & 1 & 3 & 3 & 3 & 1 & 120 \\
\hline 14 & Medical issues \& Human Physiology research & Prophylactic medical and surgical measures & 3 & 3 & 2 & 3 & 1 & 3 & 1 & 120 \\
\hline 15 & Operations & Maintenance and repair & 2 & 3 & 2 & 2 & 3 & 3 & 1 & 120 \\
\hline 16 & Crew Rescue, Safety \& Survivability & Emergency training & 2 & 3 & 2 & 3 & 3 & 2 & 1 & 118 \\
\hline 17 & Crew Rescue, Safety \& Survivability & Safe Haven & 3 & 3 & 1 & 2 & 3 & 3 & 1 & 118 \\
\hline 18 & Science & Planetary science (geology, astrobiology) & 3 & 1 & 3 & 2 & 3 & 3 & 3 & 118 \\
\hline 19 & Transportation & Human transport (e.g. CEV) & 3 & 3 & 2 & 1 & 3 & 3 & 1 & 118 \\
\hline 20 & Communication & Earth Mars relay satellite(s) & 2 & 2 & 2 & 2 & 3 & 3 & 3 & 117 \\
\hline 21 & Extravehicular Activity (EVA) & Decontamination & 3 & 3 & 1 & 2 & 3 & 2 & 3 & 117 \\
\hline 22 & Medical issues \& Human Physiology research & $\begin{array}{l}3 / 8 \mathrm{~g} \text { medical procedures } \\
\text { (including diagnostics and treatments) }\end{array}$ & 2 & 3 & 1 & 2 & 3 & 3 & 2 & 117 \\
\hline 23 & Planetary Protection & Containment & 3 & 3 & 1 & 2 & 3 & 2 & 3 & 117 \\
\hline 24 & Planetary Protection & Sterilization & 3 & 3 & 1 & 2 & 3 & 2 & 3 & 117 \\
\hline 25 & Planetary Protection & Guidelines for human missions (procedures) & 3 & 3 & 1 & 2 & 3 & 2 & 3 & 117 \\
\hline 26 & Habitation (Mars Surface) & Pre-deployed habitat & 2 & 3 & 1 & 2 & 3 & 3 & 1 & 113 \\
\hline 27 & In situ resource utilization (ISRU) & Water extraction from surface & 3 & 2 & 1 & 2 & 3 & 3 & 2 & 111 \\
\hline 28 & Operations & Construction & 3 & 3 & 1 & 1 & 3 & 3 & 1 & 111 \\
\hline 29 & Science & Life sciences (human physiology, plants growth) & 3 & 1 & 2 & 2 & 3 & 3 & 3 & 111 \\
\hline 30 & Power Generation and Storage & Nuclear Reactor & 3 & 3 & 2 & 1 & 1 & 3 & 2 & 110 \\
\hline 31 & Operations & Contingency training & 3 & 3 & 1 & 2 & 3 & 2 & 1 & 109 \\
\hline 32 & Medical issues \& Human Physiology research & Sexual management strategy & 2 & 3 & 1 & 3 & 1 & 3 & 1 & 108 \\
\hline 33 & Operations & Skills training & 2 & 3 & 1 & 2 & 3 & 2 & 2 & 108 \\
\hline 34 & Habitation (Mars Surface) & Advanced construction materials & 3 & 2 & 1 & 2 & 3 & 3 & 1 & 107 \\
\hline 35 & Life Support Systems (LSS) & On-board salad machine & 2 & 1 & 3 & 3 & 3 & 2 & 2 & 107 \\
\hline 36 & Operations & Mission control aspects & 2 & 2 & 3 & 2 & 3 & 2 & 1 & 107 \\
\hline 37 & Life Support Systems (LSS) & Food production \& storage & 2 & 2 & 1 & 2 & 3 & 3 & 2 & 106 \\
\hline 38 & Habitation (Mars Surface) & Inflatable structures & 3 & 2 & 1 & 3 & 3 & 2 & 1 & 105 \\
\hline 39 & Crew Comfort \& Welfare & Surface stay & 3 & 1 & 2 & 2 & 3 & 3 & 1 & 103 \\
\hline 40 & Propulsion & Nuclear thermal propulsion & 3 & 3 & 1 & 1 & 1 & 3 & 2 & 103 \\
\hline 41 & In situ resource utilization (ISRU) & $\begin{array}{l}\text { Propellant production technologies from local } \\
\text { ressources }\end{array}$ & 2 & 2 & 1 & 2 & 3 & 3 & 1 & 102 \\
\hline 42 & Habitation (Mars Surface) & Living, working area, greenhouses & 3 & 1 & 1 & 2 & 3 & 3 & 2 & 100 \\
\hline 43 & Life Support Systems (LSS) & Low Pressure Greenhouse & 2 & 2 & 1 & 1 & 3 & 3 & 2 & 99 \\
\hline 44 & In situ resource utilization (ISRU) & Construction from local materials (cave, regolith) & 2 & 1 & 1 & 3 & 3 & 3 & 1 & 98 \\
\hline 45 & Propulsion & Advanced chemical propulsion & 2 & 3 & 1 & 2 & 3 & 1 & 1 & 95 \\
\hline
\end{tabular}




\section{Science}

Planetary science and life science can be conducted on Mars; therefore, procedures should be tested on the Moon.

\section{Communication}

Relay communication satellites will be used for a permanent link between Mars and the Earth. These technologies can be tested on the Moon by using a site that is not in line-ofsight of the Earth.

\section{Planetary Protection}

Major technologies in this area include containment, sterilization, and procedures for human missions. These can be tested on lunar missions prior to a Mars mission.

\section{$\underline{\text { In Situ Resource Utilization }}$}

Construction from local materials, water extraction from the surface, and propellant production from local resources are the three main categories to be tested on the Moon.

\section{Power Generation and Storage}

Use of nuclear reactors will be necessary for long-duration missions on the surface of Mars. While reactors have been tested in space, they have not yet been tested on other planetary surfaces.

\section{Life Support Systems}

Bioregenerative life support systems that allow food production and storage will require low pressure greenhouses. These systems provide self-sufficiency and may reduce cost.

\section{Crew Comfort and Welfare}

Astronaut well-being is crucial to mission success; therefore, crew comfort during the surface stay is an important element to be tested. Considerations include privacy, food preparation and diet, sleeping quarters, showers and toilets, spare-time activities, and communication with family and friends.

\section{Propulsion}

Nuclear thermal propulsion and advanced chemical propulsion will be necessary for the Mars transit and for lift-off from the martian surface, respectively. To ensure technology readiness, these technologies could first be tested during a lunar mission.

The selected enabling elements that can best be tested on the Moon, as listed in Table 4, are an input to the rehearsal missions to the Moon summarized in Section 5.

\section{Rehearsal Missions to the Moon}

The previous sections of this paper laid the groundwork for planning rehearsal missions to the Moon, including a summary of current international plans for missions to the Moon and Mars; the necessary political, social, and legal aspects; and the enabling elements best tested on the Moon.

This section provides a description and roadmap of the LunAres program to rehearse the enabling elements identified in Section 4. Four mission categories of increasing complexity are identified. These types of missions culminate in a long-stay human lunar mission. The recommendations are captured in Section 6, Conclusions and Recommendations.

\section{Mission Categories}

To rehearse the enabling elements identified in Section 4, four categories of increasingly complex missions have been identified and are discussed below.

Type 1 - Robotic Missions

These include uncrewed missions for remote sensing, resource mapping, technology testing, and automated science experiments.

\section{Type 2 - Preparation Missions}

These include demonstration of essential technologies for a human mission and early deployment of habitats and other infrastructure elements.

Type 3 - Human Short-stay Missions

These include human missions for a few days on the lunar surface.

\section{Type 4 - Human Long-stay Missions}

These are defined as human missions of up to three years on the lunar surface.

Figure 1 is a roadmap of the recommended missions that are discussed on the following pages.

\section{Robotic Missions}

The objectives of the preliminary robotic missions are:

- To demonstrate soft and precision landing

- To demonstrate surface Guidance, Navigation, and Control (GNC) capabilities

- To demonstrate automatic sample return

- To test technologies for probe sterilization, power transmission, and radiation measurement

A Lunar Sample Return Mission (LSR), based on NASA's concept for a Moonrise mission, is recommended for launch in 2009. The primary purpose of this mission is to study the Aitken Basin and to return samples to Earth. However, 
power-transmission and radiation-monitoring technologies

could be tested during the mission as well.

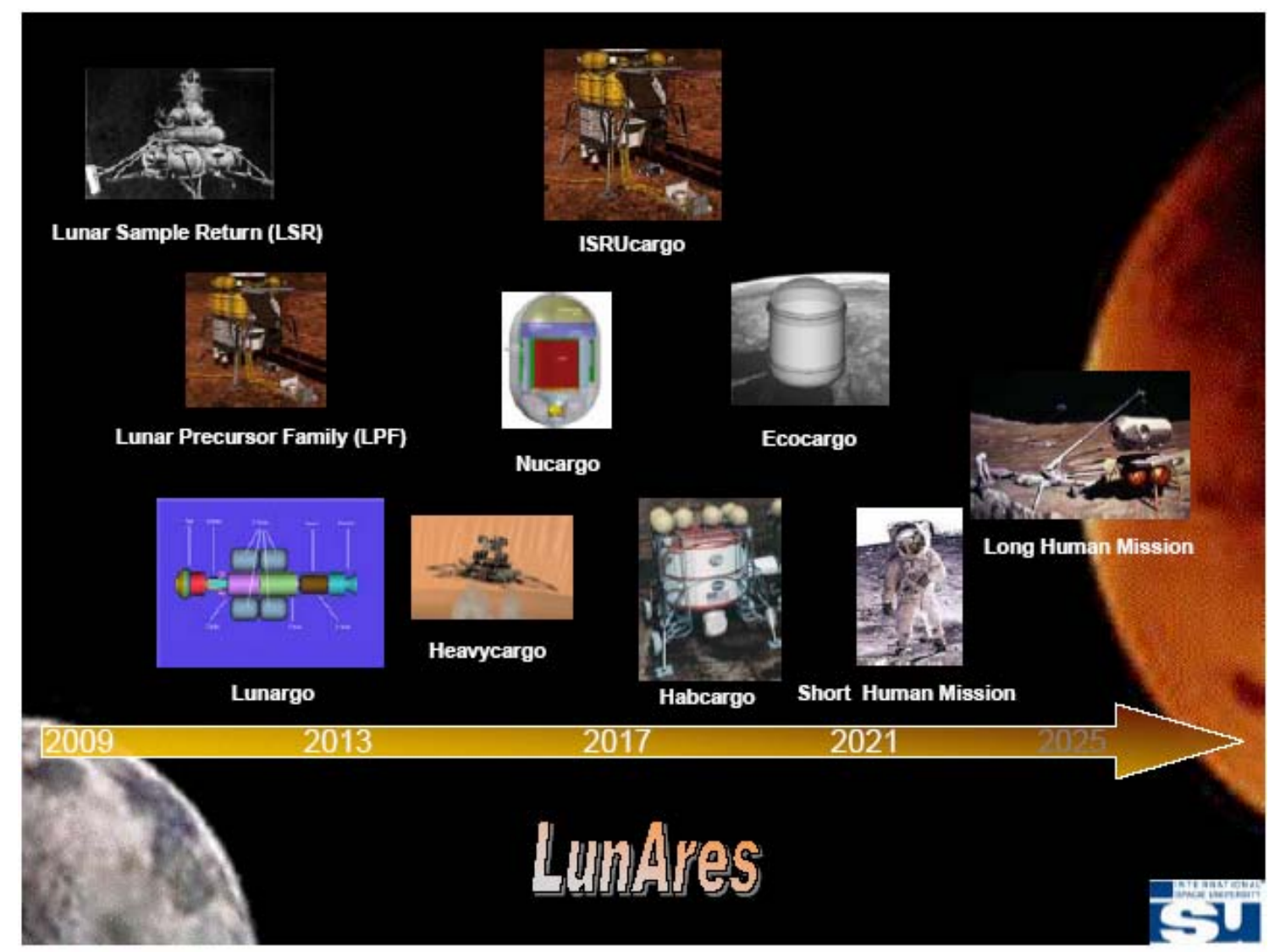

Figure 1. Roadmap for LunAres Program

A set of missions, the Lunar Precursor Family (LPF), is recommended to allow standardized payload interfaces. The LPF includes a Lunar Soft-Lander Demonstrator (LSLD), ISRU Demonstrators I-IV (IDEM), Inflatable Structure Experiment (ISE), Automated Plant Growth Experiment (APEX), and a Construction Rover.

Using a common spacecraft bus and interchanging only the payload would allow these missions to be launched within a relatively short time frame and at a lower cost than designing a new spacecraft for each mission. These missions are envisioned to be lightweight (under $500 \mathrm{~kg}$ ) and capable of being launched on a Delta II or Ariane V.

The LSLD mission objectives are to demonstrate precision and soft landing capability on the Moon, and to identify water in the lunar south pole regions. The IDEM missions will demonstrate different ISRU processes and consist of five spacecraft, each using a common bus. ISE, a precursor to a plant growth experiment, will demonstrate precision landing and the use of inflatable structures on the Moon.
APEX will demonstrate plant growth in the lunar pole and will consist of a small inflatable low-pressure greenhouse (ILPG). The Construction Rover will demonstrate the use of unprocessed lunar regolith by moving dirt, burying radiometers, and testing lunar regolith properties. A subsurface water and ice detection science instrument will also be sent to the Moon. A social piggyback payload is recommended to enable the long-term sustainability of the LunAres program. This payload could include memory devices that contain messages from the public or a small robot that builds a monument using lunar regolith.

For more information regarding each robotic mission, the reader is referred to the LunAres Final Report [1].

\section{Cargo Preparation Missions}

Following the robotic precursor missions, preparation cargo missions will be sent to the Moon. This cargo will include inflatable structures, a nuclear reactor, an ISRU reactor, a habitation module, and a greenhouse. Each mission will be 
designed such that the cargo can be included as a payload on the same spacecraft bus.

\section{Heavycargo}

Heavycargo missions will include inflatable structures and robotic units. These missions will demonstrate on-orbit spacecraft assembly, heavy-landing capability (10-15 metric tonnes), and inflatable structure deployment.

\section{NUCargo}

The second planned cargo mission, with a mass budget of $7000 \mathrm{~kg}$, will include the nuclear reactor. The main demonstration of this mission will be deploying the radiators of the reactor and starting up the reactor.

\section{$\underline{\text { ISRUCargo }}$}

The ISRU will be sent during the third cargo mission, which will have a mass budget of $7200 \mathrm{~kg}$. The purpose of this mission will be to demonstrate applicable ISRU processes on the Moon and an ISRU system for use on Mars.

\section{HABcargo}

The fourth mission will send a habitation module with an expected mass of between 65 to 75 tonnes (based on the mass required for a habitation module necessary for Mars). This mission will test the Mars habitation module on the Moon. The habitation will be modular, due to its heavy mass, and will be sent in a series of missions. The modules will include a habitation structure, crew accomodations, ECLSS and thermal control, communication equipment, airlock, and EVA and science equipment. The launch vehicle is assumed to have an approximate 10 tonne lifting capability.

\section{$\underline{\text { ECOcargo }}$}

The fifth and final cargo mission will include an inflatable low-pressure greenhouse, with a mass budget of $22,300 \mathrm{~kg}$. The greenhouse is planned to provide 55 percent of the food required for a crew of six astronauts.

To accomplish these heavy cargo missions, the development of a heavy-lift launch vehicle will be necessary. Reliable automated docking capabilities will also be required. It may be possible to use a low-thrust propulsion system, such as the Nuclear Electric Propulsion (NEP) system.

\section{Short-stay Human Lunar Mission}

Short-stay human missions will begin at the lunar south pole. The first mission will last 14 days, though this duration may need to be revisited depending on the allowable risk level. A short-stay mission is proposed to reclaim lost experience (it has been over 35 years since the United States sent astronauts to the Moon) and to help reduce risk during subsequent missions. During this shortstay human mission, all elements necessary for long-stay human missions will be tested.
The expected activities for the short-stay mission include skills training, life science, surface-stay countermeasures, safe haven, airlock testing, advanced planetary suits, containment, and sterilization technology. In addition, the habitability of the habitation module will be verified, human adaptation to lunar gravity will be analyzed, and EVA equipment and procedures will be tested.

A crew of six is proposed for the short-stay mission. However, it is feasible that part of this crew will remain in low lunar orbit (LLO). Using a schedule similar to ISS, this will allow 14 days x 6 humans x 8 hrs/(day human) for a total of 672 hours of work. Sending only two crew to the lunar surface is also an option, though this might not provide enough manpower to complete all planned activities.

\section{Long-stay Human Lunar Mission}

The main objective of the long-stay human lunar mission is to demonstrate technologies for a mission to Mars. For this reason, the mission will have a crew of six people.

\section{$\underline{\text { Mission Objectives }}$}

The main objectives of this mission are to:

- $\quad$ Land a human crew on the Moon by 2020 for 450 days and return them safely

- Demonstrate enabling elements needed to support a human presence on Mars

- Continue the construction of a lunar base

- Test the vehicle building blocks for use in Mars missions

\section{Mission Sequence}

Figure 2 depicts the mission sequence for the long-stay human mission.

\section{Exploration Transfer Vehicle (ETV)}

The ETV is a modular human-rated spacecraft consisting of the following modules: crew transport/rescue vehicle, interplanetary crew transport vehicle, crew surface lander/crew ascending vehicle, propulsion unit, and power unit.

\section{Lunar Surface Operations and Testing}

The lunar surface operations will closely imitate those expected during a Mars human mission. They will consist of surface stay countermeasures, social activities, inflatable structures, building construction using regolith, and food production and storage.

Once crew members activate the base, they will be trained for emergencies and begin life science experiments. Expeditions will begin, starting with short-range and building up to medium- and long-range EVAs. The 
medium- and long-range EVAs will test surface mobility units (SMUs). Additionally, the social aspect of this longstay mission is one of the most important issues. The crew will need regular contact with family and friends on Earth

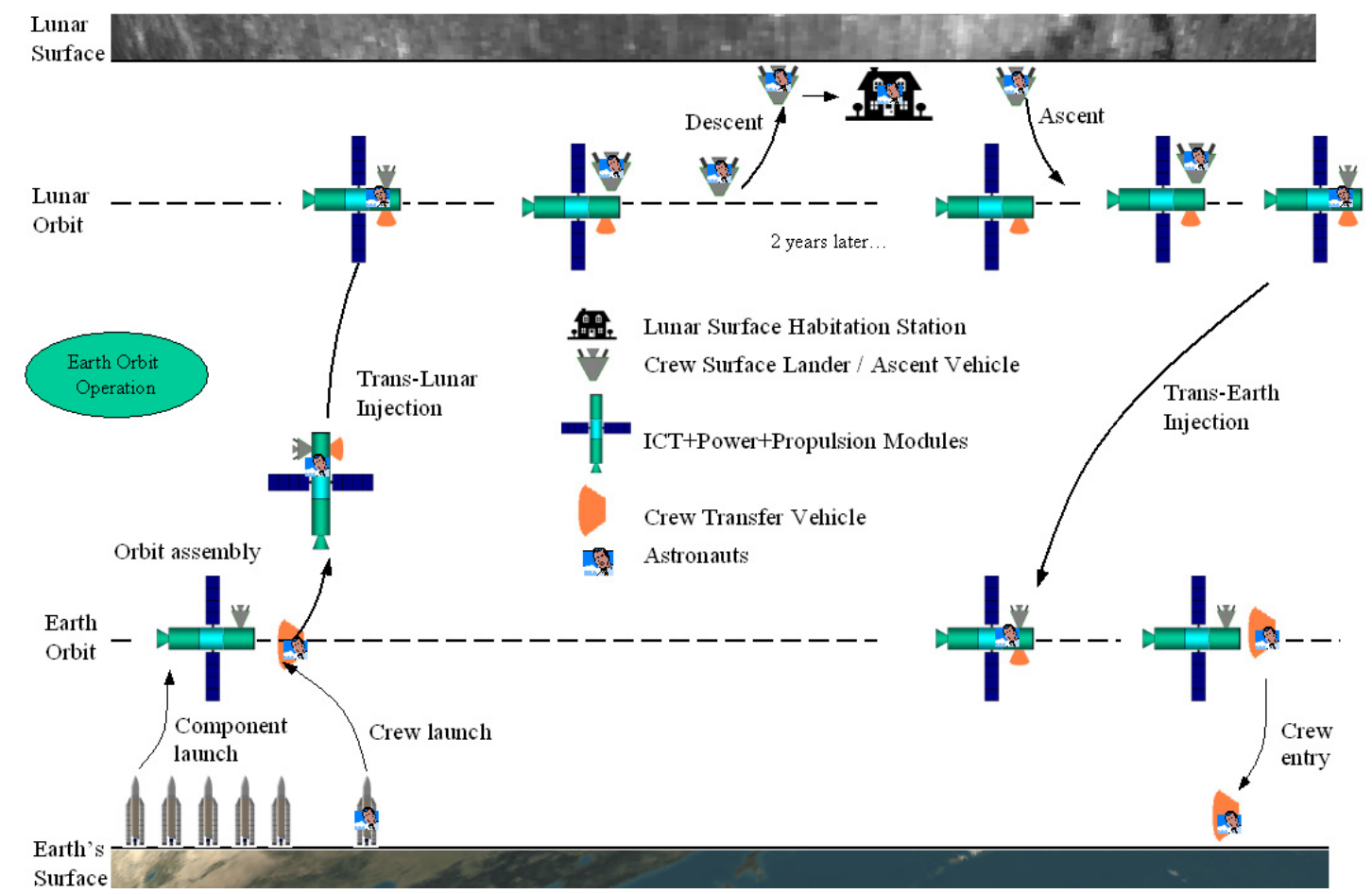

and the opportunity to participate in sports and other social activities.

Figure 2. Long-Stay Human Mission Sequence

\section{Medical and Psychological Aspects of Rehearsal Lunar Missions}

The medical and psychological aspects will be a high priority for the Moon and Mars missions. The following elements can best be tested on the Moon: acute and chronic radiation exposure, exercise countermeasures, continual training for the crew medical officer, critical care, and ambulatory facilities. In addition, these elements may need to be rehearsed: standards for palliative care, pain management and death, sexual health, and birth control measures to limit the risk of pregnancy. Psychological countermeasures will need to be developed, and strategies to limit psychosocial stressors should be instituted.

\section{CONCLUSIONS AND RECOMMENDATIONS}

The comprehensive report written during the Summer Session Program 2004 of the International Space University provides a set of 28 recommendations intended to guide the future of space exploration [1]. These recommendations include measures to handle uncertainties and to ensure that the program is flexible and sustainable.
Of the 28 recommendations, the six most important, which appear in the Executive Summary of the LunAres report, are [21]:

- Test on the Moon those elements of a human Mars mission identified as best suited to lunar rehearsal.

- Emphasize human-driven mission elements, including psychosocial issues, medical factors, and operations.

- Conduct lunar science that yields knowledge useful to preparation for a human Mars mission, contributes to sustainability by attracting public support, or promises significant scientific return at a relatively small additional cost.

- Demonstrate both operational and technical implementation of in situ resource utilization on the Moon while paying special attention to the aspects that are transferable to Mars and favoring approaches that support a sustained presence on the Moon. 
- Choose one or more potential transition or exit strategies to be implemented upon completion of the lunar rehearsal program. These strategies should be designed to ensure availability of resources for Mars exploration while supporting, to the greatest extent practical, a sustained presence on the Moon.

- Establish an international coordinating body, the Space Exploration Forum (SEF), composed of a Legal, a Technical, and a Social Outreach Advisory Board.

\section{REFERENCES}

[1] International Space University, LunAres: International Lunar Exploration in Preparation for Mars. Team Project Final Report, ISU Summer Session Program 2004, Adelaide, Australia.

[2] NASA 2004, The Vision for Space Exploration.

[3] Bonnet, RM and Swings, JP 2004, The Aurora Programme, ESA Publication Division, Noordwijk.

[4] Spudis, PD 1996, The Once and Future Moon, Smithsonian Institution, Washington.

[5] Mendell, WW 1985, Lunar Bases and Space Activities of the $21^{\text {st }}$ Century, Lunar and Planetary Institute, Houston.

[6] Hoffman, SJ and Kaplan, DL 1998, Addendum (Update) to Human Exploration of Mars: The Reference Mission of the NASA Mars Exploration Study Team, JSC Exploration Office, Houston, viewed 6 August 2004, http://ares.jsc.nasa.gov/HumanExplore/Exploration/EX Library/Exdocuments.htm\#202.

[7] Ichiro, N., Kohtaro, M., Tatsushi, I., and Ryuichi, N. 2002, "System Design Status of SELENE-B", in 23th InternationalSymposium on Space Technology and Science, Matsue, pp. 1866-1871.

[8] Sho, S., Takashi, K., Hiroaki, A., Hiroshi, K., Manabu, K., Yasuharu, K., Yoji, K., Kohtaro, M., Makiko, O., Tatsuaki, O., Kazuto, S., Takamitsu, S., and Sachiko, W. 2002 "Geological Exploration on the Lunar Surface Using Rover-lander System: A Scientific Proposal for SELENE-B", in 23th International Symposium on Space Technology and Science, Matsue, pp. 1896-1899.

[9] Astronotes 2004, June 7 (China Spells Out Lunar Plans), viewed 08 August 2004, http://www.space.com/astronotes/astronotes.html.
[10] Space today 2004, China's Moon Flights, viewed 17 August 2004, http://spacetoday.org/China/ ChinaMoonflight.html.

[11] Cline, L., Finarelli, P., Gibbs, G., and Pryke, I. 2002, Structuring Future International Cooperation: Learning from the ISS, Kluwer Law International, The Hague, Netherlands.

[12] Jasentuliyana, N. 1999, International Space Law and the United Nations, Kluwer Law International, The Hague, Netherlands.

[13] Aldridge, EC Jr, et al 2004, A Journey to Inspire, Innovate, and Discover, President's Commission on Implementation of the United States Exploration Policy.

[14] Joint Strike Fighter Program Office 2004, Joint Strike Fighter Program, viewed 8 August 2004, http://www.jsf.mil/IEFrames.htm.

[15] ISS Intergovernmental Agreement, Article 1.

[16] DIN (Deutsches Institut für Normung) 2000, Economic Benefits of Standardization, DIN Deutsches Institut für Normung, Berlin, viewed 17 August 2004, ftp://ftp.din.de/pub/executive_summary_en.pdf.

[17] Air University 1994, SpaceCast 2020, Air Education and Training Command, United States Airforce, viewed 17 August 2004, http://www.au.af.mil/Spacecast/.

[18] The Planetary Society 2004, Red Rover Project, viewed 18 August 2004, http://www.planetary.org/rrrr/.

[19] Mendell, WW, Personal Communication

[20] Craig, M. 1989, Human Exploration of the Moon and Mars - Summary of the 90-Day Study, NASA Technical Study Group.

[21] International Space University, LunAres: International Lunar Exploration in Preparation for Mars. Team Project Executive Summary, ISU Summer Session Program 2004, Adelaide, Australia.

\section{ACKNOWLEDGEMENTS}

The work described in this publication was performed at the International Space University Summer Session Program 2004 in Adelaide, Australia. Team LunAres would like to acknowledge the generous support of our sponsors: the ESA, NASA, and Optech, Incorporated.

The LunAres team members include: 
David Agnolon, Mark Avnet, Julie Bellerose, Jérôme Bertrand, Kirsten Beyer, Torsten Bieler, David Broniatowski, Tina Büchner, Ella Carlsson, Felipe Dengra, Paolo De Pascale, Felipe Dengra, James Doran, Kilian Engel, Elvina Finzi, Mindy Gallo, Hubert Gleissner, Robert Gresch, Natalie Hirsch, Defeng $\mathrm{Hu}$, Inka Hublitz, David Iranzo, Jean-Sébastien Joyal, Alf Junior, Christyne Legault, Cindy Mahler, Jose Marmolejo, Lynn Moran, Hisashi Nakamura, Anne Pacros, Eniko Patkós, Thomas Peters, Sandra Podhajsky, Matthias Raif, Amal Rakibi, Stefanie Reinecke, Jiabai Rui, Subhajit Sarkar, Michael Schiffner, Fernando Simoes, Stefan van Raemdonck, James Waldie, Gertraud Wisiak, Diane Wong, Tsutomu Yamanaka, Guoqiang Zeng, Yonghuang Zheng, and Xudong Zhou.

\section{BIOGRAPHY}

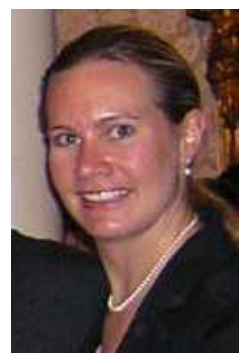

Mindy Gallo is a Principal Systems Engineer in the Advanced Programs Group at Orbital Sciences Corporation and is currently the Requirements Lead for NASA's Concept Exploration and Refinement study. She has over seven years of engineering and management experience at Orbital Sciences Corporation, Massachusetts Institute of Technology, and Pratt and Whitney, A United Technologies Company. Mindy is a candidate for an M.S. in Systems Engineering from The George Washington University. She is a graduate of the International Space University Summer Session Program 2004 and holds a S.M. in Aeronautics and Astronautics from Massachusetts Institute of Technology and a B.S. in Aerospace Engineering from the University of Virginia. In addition, Mindy has co-authored three other technical papers on the topic of risk management and use of expert systems in human space flight experiment.

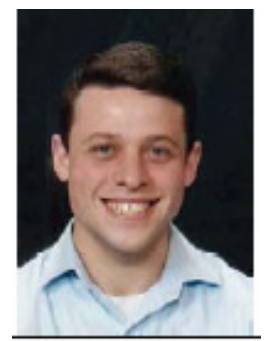

Mark Avnet is a candidate for an M.A. in International Science and Technology Policy with a focus in space policy at The George Washington University. He holds an S.B. in Physics from the Massachusetts Institute of Technology and is a graduate of the International Space University Summer Session Program 2004. Mark has worked as a research assistant at GWU's Space Policy Institute and has conducted research at NASA Ames Research Center. He currently works in the Exploration Systems Mission Directorate at NASA Headquarters.

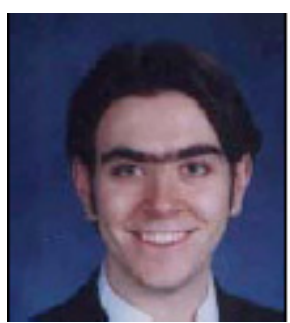

David André Broniatowski is a candidate for Master's degrees in Aeronautical \& Astronautical Engineering and Technology and Policy at the Massachusetts Institute of Technology (MIT), working in the field of space policy. David is a graduate of the International Space University Summer Session Program 2004 and holds an S.B. in Aeronautics and Astronautics from Massachusetts Institute of Technology. 